\title{
Los goliardos en la literatura del Siglo de Oro español
}

\author{
Alfonso BoIX JOVANí \\ alba_qu_bra@yahoo.com
}

\begin{abstract}
RESUMEN
Este artículo trata un personaje no muy conocido en la literatura española: el goliardo. La presente investigación intenta descubrir si los goliardos existieron en el Siglo de Oro español, pese a que Juan Ruiz es el único ejemplo claro de un goliardo en la literatura castellana. Tras un rápido repaso a la historia de los goliardos, este articulo desarrolla un análisis de diversos textos del Siglo de Oro español que, junto a los estudios desarrollados por conocidos autores, prueban que los goliardos evolucionaron en la literatura para cambiar sus papeles como autores al de personajes. Esto implica que, aunque la literatura goliárdica desapareció, ellos todavía sobrevivieron en textos que pertenecían a otros géneros, y que todavía se les puede hallar con facilidad en la literatura producida en el Siglo de Oro.
\end{abstract}

Palabras clave: goliardos, estudiantes, Siglo de Oro

\begin{abstract}
This article deals with a not very well-known character in Spanish literature: the goliard. This research attempts to find out whether goliards existed in the Spanish Golden Age, even though Juan Ruiz is the only clear example of a goliard in Castilian literature. After a quick review on the history of goliards, this article develops an analysis of several texts from the Spanish Golden Age that, together with the studies developed by well-known authors, prove that goliards evolved in literature by changing their roles as authors to become characters. This implies that, though goliardic literature disappeared, they still survived in texts that belonged to other genres, and that they can be widely found in the literature produced through the Golden Age.
\end{abstract}

Key words: goliards, students, Golden Age

\section{Introducción}

La búsqueda de la huella goliárdica en la literatura áurea obliga a conocer la historia y producción de los goliardos, la ordo vagorum, cuya existencia será fundamental para comprender, como se verá, la presencia del estudiante en los textos del Siglo de Oro.

La fama de los goliardos a partir del siglo XX se debe, con toda probabilidad, a la obra de Carl Orff Carmina Burana, inspirada en los textos hallados en torno a la abadía de Benediktbeuern (Baviera). Pero los Carmina Burana de Orff son sólo una 
breve muestra de todo el compendio de textos goliárdicos germanos, los cuales son, a su vez, un exponente de una literatura y un modo de vida que existía en toda Europa. En la propia España, Juan Ruiz no es sólo el más célebre arcipreste -Hita siempre le estará agradecida-, sino el goliardo más grande de la literatura española.

El término «goliardo» fue asociado en principio a Golias, el Goliath que matase el rey David, cuyo nombre remitía al diablo en el medievo. Pero su verdadera etimología no partía del gigante filisteo, sino de uno de los siete pecados capitales, la gula. ${ }^{1}$ Los goliardos eran eclesiásticos más interesados en comer, beber y entretenerse con mujerzuelas, así como en otros placeres terrenales, que en preparar su ascensión a los cielos. De hecho, los goliardos eran también conocidos como clerici vagantes («clérigos vagantes») debido a sus actividades, consistentes en vagabundear de aquí para allá,

fingiéndose peregrinos o cautivos recién libertados, disfrutaban dos o tres días de la hospitalidad de un monasterio, "propriis voluptatibus et gulae illecebris servientes" [...]; cuando empezaba a mirárseles con recelo, inquirían por las ermitas o los conventos cercanos y hacia allá se encaminaban; así podían transcurrir largos años. La tonsura y el traje eclesiástico les aseguraban las limosnas y una amplia inmunidad tras sus posibles excesos. ${ }^{2}$

Pienso, por otro lado, que se equivocan quienes afirman que únicamente los estudiantes podrían ser goliardos, ya que esto no se sostiene ante la terrible reprimenda del obispo Raimundo de Rocosel a un clérigo eclesiástico por ser goliardo ${ }^{3}$. Justamente, la iglesia fue el foco donde se generó no sólo la goliardía eclesiástica, sino la que, posteriormente, sería más conocida: la estudiantil. La nueva realidad del siglo XII, la de las universidades, ofrecía un nuevo campo de acción para los goliardos. ${ }^{4}$ Este nuevo terreno para sus actividades venía dado por dos elementos fundamentales: el primero, que las universidades estaban dirigidas por la Iglesia, así que los goliardos se acercarían a estos nuevos dominios eclesiásticos igual que lo hacían en torno a los monasterios; por otro lado, las universidades daban fuerza a los núcleos urbanos en los que se asentaban, de ahí que tanto la universidad como el marco en que se establecían ofrecieran un abanico de múltiples posibilidades de maniobra para los goliardos. Con esta conexión entre

\footnotetext{
${ }^{1}$ Para estos y otros interesantes datos respecto a una visión general de los goliardos, remito al estupendo «Prólogo» de C. Yarza (1981).

${ }^{2}$ C. Yarza (1981), p. 12.

${ }^{3}$ C. Yarza (1981), p. 9.

${ }^{4}$ Como explica M. Requena (2003), p. 14: «Con el auge de las universidades, toma fuerza un fenómeno curioso: el de los clérigos vagantes o giróvagos, estudiantes - no sobrados de recursos- que iban de universidad en universidad, y que llevaban una vida un tanto libre y airada [...] [,] amantes de la buena mesa, de las tabernas y del juego de los dados -motivos recurrentes en sus poemas-»».
} 
los goliardos y las universidades, el término clérigo evolucionó desde la significación de «religioso» a la de «persona cultivada». ${ }^{5}$ La conexión íntima entre goliardos eclesiásticos y estudiantiles queda, asimismo, probada por los tres mayores compendios de su producción poética: los Carmina Burana (Benediktbeuern, Baviera, Alemania) y los Carmina Rivipullensia (monasterio de Ripoll, Cataluña, España) son todos nacidos en torno a monasterios, mientras que los Carmina Cantabrigensia provienen de la Universidad de Cambridge (Inglaterra) $\mathrm{y}$, por tanto, de un foco estudiantil. De ahí que la forma clericus sirva para denominar a los goliardos tanto religiosos como estudiantes. ${ }^{6}$

En principio, la imagen del goliardo como el estudiante universitario que se dedicaba a la dolce vita, amigo de prostitutas, amante del juego y habitante de las tabernas parecerá una idea absolutamente romántica: la vida de un personaje que vive más allá de ley, relacionándose con los estratos sociales más bajos puede llevar a la confusión entre la idea de libertad y libertinaje. Por desgracia, no todos los goliardos lo eran por gusto $\mathrm{y}$, en muchos casos, se debía a que su pobreza les obligaba a llevar la «mala vida» que les hizo célebres. Además del estudiante rico (con criado), los más eran pobres y, a fin de pagarse los estudios, se dedicaban al juego, así como a mil y una triquiñuelas que les permitiesen obtener algún sustento. ${ }^{7}$ Tal parece indicarse en el capítulo 8 del Guitón Onofre:

Había en la posada un estudiante que iba a Salamanca a estudiar, al parecer principal. Al fin, llevaba un criado de a pie y otro de a caballo; y no queráis más, que la nobleza anda en tal estado, que la tiene el que tiene. ${ }^{8}$

La gran pregunta, en primer lugar, se centraría en saber si había lugar en el Siglo de Oro español para los goliardos. El concilio de Trento atestigua su existencia y peligrosidad en Europa, pero no se refiere a los goliardos estudiantiles en concreto

${ }^{5}$ De acuerdo con M. Requena (2003), p. 14. «Clérigo significaba entonces instruído, hubiese recibido o no alguna orden sagrada; pero la mayoría de estos escolares había recibido, al menos, la tonsura, para poder aspirar a algún beneficio eclesiástico».

${ }^{6}$ El Diccionario de la Real Academia de la Lengua Española (1992), p. 737, en su segunda definición para la entrada goliardo, da, indica lo siguiente: «En la Edad Media, clérigo o estudiante vagabundo que llevaba vida irregular». Por su parte, Covarrubias (1979) habla de los «bagamundos» o «vagamundos» en la entrada del verbo «Vagar», dentro de su Tesoro, aunque esto no implica en principio su existencia, ya que no especifica que sean eclesiásticos o estudiantes.

${ }^{7}$ J. Paul (2003), p. 359 explica la penosa situación de buena parte de los estudiantes de la época: «hay pobreza entre los estudiantes. Por uno que tiene la bolsa bien llena y un criado para llevarle los libros, hay muchos que apenas pueden pagarse un alquiler» de ahí que algunos viviesen «en la calle, sin amparo alguno, entregados al vagabundeo y a las malas compañías».

${ }^{8}$ Cito por G. González (2001), p. 367. 
sino a los vagos en general, ${ }^{9}$ incluyendo a los eclesiásicos, lo cual resulta interesante al apreciarse que esta clase de goliardos no había desaparecido con el medievo. $^{10}$

Pero, en lo que al goliardo estudiantil respecta, es necesario contemplar la posibilidad de que existiesen los dos tipos que también había en la Edad Media entre los clérigos: los que se veían forzados a vagabundear y a la mala vida por la pobreza en que vivían, y los que eran vagos por placer. Para el primer grupo, siendo estos el resultado de un determinismo infausto que les mantenía en la escasez de medios, todo dependerá de si existieron todavía en los siglos XVI y XVII esas circunstancias adversas que permitían la existencia de estudiantes pobres. Sin ese contexto adecuado, sin ese caldo de cultivo de espíritu goliárdico, el presente estudio se vería abocado a un temprano final. Evidentemente, la situación universitaria no era la misma en el siglo XVI que en el XII, y no es el propósito de este trabajo analizar concienzudamente la situación universitaria de la época ya que, ni es el principal objeto de estudio, ni tendría sentido a la vista de los magníficos trabajos ya existentes al respecto. ${ }^{11}$

${ }^{9}$ «Multi sunt, qui vagantur, et incertas habent sedes, et, ut improbi sunt ingenii, prima uxore relicta, aliam, et plerumque plures, illa vivente, diversis in locis ducunt. Cui morbo cupies sancta Synodus occurrere, omnes, ad quos spectat, paterne monet, ne hoc genus hominum vagantium ad Matrimonium facile recipiant: magistratus etiam sæculares hortatur, ut eos severe coerceant. Parochis autem præcipit, ne illorum matrimoniis intersint, nisi prius diligentem inquisitionem fecerint, et re ad Ordinarium delata, ab eo licentiam id faciendi obtinuerint» [«Muchos son los que andan vagando y no tienen mansion fija, y como son de perversas inclinaciones, desamparando la primera mujer, se casan en diversos lugares con otra, y muchas veces con varias, viviendo la primera. Deseando el santo Concilio poner remedio á este desórden, amonesta paternalmente á las personas á quienes toca, que no admitan fácilmente al Matrimonio esta especie de hombres vagos; y exhorta á los magistrados seculares á que los sujeten con severidad, mandando además á los párrocos, que no concurran á casarlos, si antes no hicieren exactas averiguaciones, y dando cuenta al Ordinario obtengan su licencia para hacerlo.»]. La cita y la traducción se realizan a partir de El Sacrosanto y Ecuménico Concilio de Trento (1857), sesión XXIV. Evidentemente, esta amonestación es para todo tipo de vago, sin que sea necesariamente un estudiante.

${ }^{10}$ Concilio de Trento (1857), Sesión XXII: «Deinde, ut irreverentia vitetur, singuli in suis diœcesibus interdicant, ne cui vago, et ignoto sacerdoti Missas celebrate liceat» [«Despues de esto, para que se evite toda irreverencia, ordene cada Obispo en sus diócesis, que no se permita celebrar Misa á ningun sacerdote vago y desconocido»] . El Concilio hace también referencia a un tipo de canto muy propio de los goliardos eclesiásticos: «Ab ecclesiis vero musicas eas, ub sive organo, sive cantum lascivum, aut impurum aliquid miscetur» [«Aparten tambien de sus iglesias aquellas músicas en que ya con el órgano, ya con el canto se mezclan cosas impuras y lascivas»]. La cita y la traducción provienen de El Sacrosanto y Ecuménico Concilio de Trento (1857), Sesión XXII.

${ }^{11}$ Para ampliar conocimientos en torno al mundo universitario del período áureo español, así como del resto de épocas, existe una numerosa bibliografía, de entre la que me permito 
Si cambiaron las perspectivas - del teocentrismo medieval al antropocentrismo-, así como las legislaciones y otros muchos asuntos, la pobreza seguía allí. Torremocha lo demuestra e, incluso, indica cómo la Universidad de Valladolid otorgaba lo que hoy llamaríamos «becas» a los estudiantes pobres y, como la misma autora advierte, «pobreza y falta de asistencia a las aulas se relacionaban» ${ }^{12}$.

Es seguro que también habría estudiantes que, pese a un nivel económico solvente, se dedicarían a los vicios justo por el hecho de tener dinero para permitírselo, ${ }^{13}$ tipo que sería el equivalente áureo al monje medieval que se dedicaba a la goliardía por falta de vocación religiosa. Pero no debemos confundir las actividades propias de los goliardos, sean de uno u otro tipo, con las gamberradas y novatadas generalizadas y propias de los estudiantes que, obviamente, no requerían ser goliardos para ejecutarlas, como en los repelones del Auto del Repelón de Juan del Encina o, por ejemplo, la que hallamos en El Buscón de Quevedo, basada en elementos escatológicos:

[Dice don Pablos] Entré en el patio [en Alcalá], y no hube metido bien un pie, cuando me encararon y empezaron a decir: $-« i N u e v o ! »$. Yo, por disimular, di en reír, como que no hacía caso; mas no bastó, porque, llegándose a mí ocho u nueve, comenzaron a reírse. Púseme colorado; nunca Dios lo permitiera, pues, al instante, se puso uno que estaba a mi lado las manos en las narices y, apartándose, dijo:

-Por resucitar está este Lázaro, según olisca.

Y con esto todos se apartaron, tapándose las narices. Yo, que me pensé escapar, puse las manos también y dije:

$-\mathrm{V}$. Mds. tienen razón, que huele muy mal.

Dioles mucha risa y, apartándose, ya estaban juntos hasta ciento; comenzaron a escarrar y tocar al arma, y en las toses y abrir y cerrar de las bocas, vi que se me aparejaban gargajos. En esto, un manchegazo acatarrado hízome alarde de uno terrible, diciendo:

-Esto hago.

Yo entonces, que me vi perdido, dije:

- Juro a Dios que te ma...!

Iba a decir te, pero fue tal la batería y lluvia que cayó sobre mí, que no pude acabar la razón. Yo estaba cubierto el rostro con la capa, y tan blanco, que todos tiraban a mí; y era de ver cómo tomaban la puntería. ${ }^{14}$

Hoy día, en muchas universidades todavía se practican las novatadas, pero no por

destacar a J. Simón-Díaz (1966), P. Jacques (2003), C. Maria Ajo González de Rapaniegos y Sáinz de Zúñiga (1959-1972), y el estupendo trabajo de M. Torremocha (1998).

${ }_{12}$ M. Torremocha (1998), pp. 91-99.

${ }^{13}$ Advierte M. Torremocha (1998), p. 95 que algunos estudiantes con dinero «se distraían con costosas diversiones olvidando acudir a las clases»».

${ }^{14}$ Cito por F. de Quevedo (1993), pp. 86-87. 
ello diremos que los ejecutores sean goliardos, ya que se trata de actividades comunes entre estudiantes, y así parece que debían serlo en aquella época. El texto de Quevedo no parece implicar que fuesen estudiantes vagos los agresores de don Pablos, sino una masa generalizada.

Pero,¿qué es realmente la literatura goliárdica? ¿Existe una temática propiamente goliárdica? $\mathrm{O}$, mejor dicho, ¿qué hace de un texto que sea puramente goliárdico? El poco reverente (incluso, posiblemente blasfemo) Canción a Cristo Crucificado no es obra de goliardo alguno, sino de Francisco de Aldana, aunque podría recordar a textos goliárdicos como el Evangelio según San Marco de Plata medieval, y los textos medievales de amor cortés no son obras de goliardos sino de nobles, pese a guardar similitudes entre sí. ${ }^{15}$

Creo que la característica de la literatura goliárdica no radica en su temática sino en su autor. Es cierto que los goliardos trataban unos temas con mayor asiduidad que otros - como el juego, la vida en la taberna, etc...-, pero también utilizaban otros -como la poesía amatoria-, que no es propiamente goliárdica. De hecho, no creo que exista ningún tema «propiamente goliárdico», en cuanto que otros escritores podrían adoptar dichos temas para su literatura. Así por ejemplo, canciones como la irlandesa Whiskey in the Jar, evidente canción tabernera, no tuvo por qué ser creada por un goliardo, sino por la propia gente tabernaria, fuesen o no estudiantes. Así, la goliardía de una obra no radica en su temática, sino en que su autor no es, en principio, alguien que debiese tratar esos asuntos. Un poema amoroso escrito por un cortesano no tiene nada de extraño, pues es bien sabido que el amor cortés era cultivado por cortesanos. Pero si el autor es un sacerdote, el impacto es evidente, pues alguien dedicado al amor divino no debería preocuparse por el amor profano. Del mismo modo, un estudiante que tratase en sus poemas temas cultos no debería de parecer anormal, teniendo en cuenta su formación, mientras que sí será goliárdico el poema redactado por una persona en principio dedicada al estudio en el que se cante a la vida en las tabernas o narrando como engañó a tal o cual persona adinerada, comportándose como un ladronzuelo sin cultura y no como alguien cultivado. Un ejemplo del ya citado contraste entre las labores que se presuponen a los clérigos y sus actividades reales queda probado en este pasaje del Guzmán de Alfarache, donde en ningún momento se habla de los estudios, reemplazados por el vicio. "Ommitamus studia», como decía el famoso canto goliárdico:

¡Oh madre Alcalá! ¿Qué diré de ti, que satisfaga, o cómo para no agraviarte callaré, que no puedo? Por maravilla conocí estudiante notoriamente distraído, de tal manera, que por el vicio, ya sea de jugar o cualquiera otro, dejase su fin principal en lo que tenía obligación, porque lo teníamos por infamia. ¡Oh dulce vida la de los estudiantes! ¡Aquel hacer de obispillos, aquel dar trato a los

${ }^{15}$ A Boix Jovaní (1999), pp. 22-26. 
novatos, meterlos en rueda, sacarlos nevados, darles garrote a las arcas, sacarles la patente o no dejarles libro seguro ni manteo sobre los hombros! ¡Aquel sobornar votos, aquel solicitarlos y adqu[i]rirlos, aquella certinidad en los de la patria, el empeñar de prendas en cuanto tarda el recuero, unas en pastelerías, otras en la tienda, los Escotos en el buñolero, los Aristóteles en la taberna, desencuadernado todo, la cota entre los colchones, la espada debajo de la cama, la rodela en la cocina, el broquel con el tapadero de la tinaja!

¿En qué confitería no teníamos prenda y taja cuando el crédito faltaba? ${ }^{16}$

En su origen, el presente estudio se planteó con la idea de tratar la existencia de una literatura goliárdica en el Siglo de Oro. Esto llevó a replantear qué era esa literatura denominada goliárdica, y ese mismo replanteamiento de la cuestión llevó a localizar una evolución de todo el asunto goliárdico, al cual me referiré seguidamente: no pudiendo hablarse de una literatura genuinamente goliardesca en los siglos áureos, los goliardos sufrieron un cambio de roles a nivel literario que daría por resultado la figura del estudiante más popular en la literatura española, pero manteniendo sus rasgos típicamente goliardescos. A todo ello dedicaré las siguientes páginas.

\section{La áurea goliardía}

\subsection{Los goliardos necesitados}

Ya se ha apuntado más arriba cómo no todos los universitarios tenían exceso de dinero. Más al contrario, la mayoría sufrían pobreza y se veían abocados a ingeniárselas con mil y un trucos para subsistir. Entre los recursos utilizados por los goliardos para sobrevivir se encuentra la demostración de su arte. Los goliardos eran también juglares, pues escribían e interpretaban sus cancioncillas a fin de obtener algunas monedas, tradición de la cual hoy es un simbólico remanente la tuna universitaria, como indica la ingente bibliografía al respecto al advertir que los sopistas - cuyo principal sustento era la sopa boba- eran una versión española de los goliardos estudiantiles europeos, portadores de cubiertos de madera, símbolo todavía de las tunas universitarias.

Además de los cantos, también se encontraba la jugarreta de embaucar a la audiencia contándoles una historia que conmoviese sus corazones... y sus bolsillos. Advertía Yarza más arriba que los goliardos medievales utilizaban entre sus trucos el fingirse «peregrinos o cautivos recién libertados», con lo cual «disfrutaban dos o tres días de la hospitalidad de un monasterio». Aunque ya no buscasen sustento en monasterios, los goliados áureos utilizaron este mismo engaño, según demuestran Los Trabajos de Persiles y Sigismunda, de Cervantes: en cierto pasaje, dos estudiantes relatan en la calle sus desventuras cuando estuvieron presos en Argel, a fin de que el público se apiade de ellos y les dé limosna. Los dos alcaldes del lugar se temen que sean unos mentirosos y les interrogan sobre Argel, pero los

${ }^{16}$ M. Alemán (1984), pp. 379-380. 
estudiantes demuestran no saber nada. Así que cuando deciden escarmentarlos, los dos jóvenes se defienden con una verborrea verdaderamente prodigiosa, hasta el punto de que se les perdona e incluso se les ayuda. La ironía es evidente. Y es que, como dice más tarde uno de los estudiantes «tal vez [...] se hurta con autoridad y aprobación de la justicia. Quiero decir, que alguna vez los malos ministros della se hacen a una con los delincuentes, para que todos coman». ${ }^{17}$

[habla un estudiante] Castíguense los que cohechan, los escaladores de casas, los salteadores de caminos, los testigos falsos por dinero, los mal entretenidos en la república, los ociosos y baldíos en ella, que no sirven de otra cosa que de acrecentar el número de los perdidos, y dejen a los míseros que van su camino derecho a servir a su Majestad con la fuerza de sus brazos y con la agudeza de sus ingenios, porque no hay mejores soldados que los que se trasplantan de la tierra de los estudios en los campos de la guerra; ninguno salió de estudiante para soldado, que no lo fuese por estremo, porque cuando se avienen y se juntan las fuerzas con el ingenio y el ingenio con las fuerzas, hacen un compuesto milagroso, con quien Marte se alegra, la paz se sustenta y la república se engrandece.

Admirado estaba Periandro y todos los más de los circunstantes, así de las razones del mozo como de la velocidad con que hablaba, el cual prosiguiendo, dijo:

-Espúlguenos el señor alcalde, mírenos y remírenos, y haga escrutinio de las costuras de nuestros vestidos, y si en todo nuestro poder hallare seis reales, no sólo nos mande dar ciento, sino seis cuentos de azotes. Veamos, pues, si la adquisición de tan pequeña cantidad de intereses merece ser castigada con afrentas y martirizada con galeras; y así, otra vez digo que el señor alcalde se remire en esto, no se arroje y precipite apasionadamente a hacer lo que, después de hecho, quizá le causara pesadumbre. Los jueces discretos castigan, pero no toman venganza de los delitos; los prudentes y los piadosos, mezclan la equidad con la justicia, y entre el rigor y la clemencia dan luz de su buen entendimiento.

-Por Dios -dijo el segundo alcalde-, que este mancebo ha hablado bien, aunque ha hablado mucho, y que no solamente no tengo de consentir que los azoten, sino que los tengo de llevar a mi casa y ayudarles para su camino, con condición que le lleven derecho, sin andar surcando la tierra de una en otras partes, porque, si así lo hiciesen, más parecerían viciosos que necesitados.

Ya el primer alcalde, manso y piadoso, blando y compasivo, dijo:

-No quiero que vayan a vuestra casa, sino a la mía, donde les quiero dar una lición de las cosas de Argel, tal que de aquí en adelante ninguno les coja en mal latín en cuanto a su fingida historia.

Los cautivos se lo agradecieron, los circunstantes alabaron su honrada determinación y los peregrinos recibieron contento del buen despacho del negocio. ${ }^{18}$

\footnotetext{
${ }^{17}$ M. de Cervantes (1985), pp. 350-351.

${ }^{18}$ M. de Cervantes (1985), pp. 349-350.
} 
Se hallan en este pasaje diversos elementos interesantes. Por un lado, el retrato costumbrista de los dos estudiantes relatando sus ficticias aventuras como prisioneros en Argel. Esta descripción permite apreciar algunas de las características de estos verdaderos artistas del engaño, pues verdadero arte es el de la improvisación. Al verse en peligro, se inventan un discurso en su defensa que no sólo les vale el perdón de los alcades y del pueblo, sino también su favor. Si se piensa detenidamente, esta improvisación tiene un gran mérito, pues, al descubrirse la verdad y exponer su lacrimógeno discurso, los estudiantes consiguen mayores beneficios de los que esperaban conseguir con su cuento original. Ahí radica gran parte de la ironía y el fino humor del pasaje, digno del genio cervantino: cuando todo parece perdido, finalmente consiguen salir ganando más de lo que incluso el propio lector podía esperar, pues ya veía a los dos pícaros como galeotes de por vida.

Otro elemento muy interesante, especialmente en cuanto a la historia de los goliardos se refiere, es el truco que utilizan, esto es, el hacerse pasar por cautivos fugados de Argel, lo cual evoca inevitablemente una de las actividades de los goliardos medievales que apunta Yarza al decir que, haciéndose pasar por «cautivos recién libertados, disfrutaban dos o tres días de la hospitalidad de un monasterio» ${ }^{19}$. La evolución de los goliardos en el texto cervantino es clara, y coincide con lo anteriormente expuesto: los objetivos de los goliardos a partir del auge universitario son los focos urbanos, por eso estos estudiantes -habituados no a los caminos, sino a las ciudades- tratan de engañar a un pueblo, no a un monasterio. Por otro lado, junto a esta demostración de las capacidades interpretativas de estos virtuosos de la improvisación, figura una interesante afirmación del segundo alcalde: al decir que los quiere invitar a su casa, advierte que ha de «ayudarles para su camino, con condición que le lleven derecho, sin andar surcando la tierra de una en otras partes, porque, si así lo hiciesen, más parecerían viciosos que necesitados». Esta afirmación entronca con la cita vista más arriba del Guzmán de Alfarache, donde los estudios eran substituidos por el vicio. Ya algunos goliardos medievales, tal vez movidos inicialmente a la mala vida por hambre, seguían posteriormente en ella no ya por necesidad sino por placer, vencidos por el vicio, ${ }^{20}$ de ahí que el segundo alcalde les advierta de que, si después de ser ayudados siguen en sus andanzas, será no ya por necesidad, sino porque les gusta la vida de perdición que llevan. Es, pues, un reflejo literario de la diferencia entre los goliardos por necesidad y los «vocacionales», si se me permite la expresión, al igual que sucede en La Vida del

\footnotetext{
${ }^{19}$ C. Yarza (1981), p. 12.

${ }^{20}$ C. Yarza (1981), p. 12 indica la existencia en la Edad Media de «clérigos entregados no ya a la vagancia, sino resueltamente a la mala vida: clérigos ajuglarados, saltimbanquis, autores de canciones obscenas y difamatorias; clérigos malhechores, rufianes, tahúres, lujuriosos; clérigos pobres -siempre-, fiados al azar y a la falta de escrúpulos».
} 
Estudiante Pobre donde, de hecho, el narrador es un estudiante pobre que conoce mil y un trucos para sobrevivir, ya que es «[...] el que más miserias passo / en esta universidad,» (vv. 1-2), frente a los dedicados al vicio no sólo por hambre, sino porque disfrutan con él, y de los que también se habla hacia el final de La Vida... Parece que este segundo grupo fue el que más huella dejó, a juzgar por J. García Mercadal (1934) quien, basándose en textos áureos, muestra a estudiantes que son más bien ladrones y traviesos por vicio que no por necesidad, una idea similar a la que transmite J. Simón Díaz (1966). M. Chevalier (1981) advertía la importancia de la necesidad, de esa lucha por la supervivencia, pero al estudiar los trucos estudiantiles, el autor los analiza desde un punto de vista centrado en la tradición folklórica y literaria que, pese a que demuestra la pervivencia del estudiante como personaje en la tradición literaria española, le lleva a afirmar que «forzosamente hemos de concluir que el folklore español del Siglo de Oro forma del estudiante concepto negativo. El estudiante es hambriento, tracista, burlón, algo ladrón, mujeriego, holgazán, ignorante y tonto». ${ }^{21}$ Creo que estas conclusiones no alcanzan a comprender toda la dimensión literaria, y aún menos históricamente social, del goliardo estudiantil.

\subsection{Los vicios goliárdicos, I: el juego.}

Uno de esos casos en que la necesidad se mezcla con el vicio se halla en el juego. Los goliardos utilizaban los dados o los naipes para obtener algún dinero en las apuestas, pero no es extraño que con el tiempo jugasen no ya sólo por la necesidad económica sino por el placer del juego, convirtiéndose en goliardos vocacionales. Los textos goliárdicos abundan en este tipo de temas, como muestra el siguiente Carmen Buranum:

In taberna quando sumus, non curamus, quid sit humus, sed ad ludum properamus, cui semper insudamus. Quid agatur in taberna, ubi nummus est pincerna, hoc est opus, ut queratur, sed quid loquar, audiatur! $!^{22}$

21 M. Chevalier (1981), p. 53. El autor muestra cómo el estudiante recoge aspectos folklóricos sólo hasta cierto punto. Principalmente, se analizan estafas, chistes y otros elementos del comportamiento estudiantil, pero esos elementos no tendrían cabida en la figura del estudiante si su carácter no fuese acorde con tales maneras. En el presente estudio, mi entronque de los estudiantes con los goliardos sí que establece una tradición, un folklorismo si así quiere decirse, del carácter del estudiante áureo, lo cual permite conocer en mayor profundidad su figura.

${ }^{22}$ La traducción, muy fiable, reza como sigue: "Cuando estamos en la taberna, / no nos 
Los ejemplos de estudiantes jugadores abundan en la literatura española áurea. Así, en el último capítulo de la Segunda parte de Lazarillo de Tormes se narra cómo Lázaro, estando en Salamanca, hace amistad con algunos estudiantes, con quienes juega a las cartas. También en las Aventuras del Bachiller Trapaza, de Alonso de Castillo Solórzano, aparecen diversas partidas de naipes

\subsection{Los vicios goliárdicos, II: la buena mesa y las mujerzuelas.}

Dos de los vicios más comunes entre los goliardos es el gusto por el buen yantar y los amoríos. Los cantos de amor goliárdicos son celebérrimos, tanto en los textos aislados como en las tres grandes colecciones, los Carmina Rivipullensia, los Carmina Cantabrigensia y los Carmina Burana. Pero, entre los placeres de Venus, se halla el contacto con las prostitutas. Nuevamente, en los Carmina Burana, hallamos un ejemplo de los principales vicios goliárdicos en el «In taberna quando summus»:

Quidam ludunt, quidam bibunt, quidam indiscrete vivunt. ${ }^{23}$

Creo que la referencia a los que «indiscrete vivunt» puede conectarse con la prostitución, ya que el juego y la bebida ya han sido nombrados. Siendo el «In taberna quando sumus» un poema tabernario, no debe de extrañarnos la presencia de prostitutas en la taberna, algo que también se daba en el Siglo de Oro. ${ }^{24}$ Ya se ha indicado con anterioridad el origen eclesiástico de los goliardos y parece ser que, en la edad áurea, los religiosos vagos no habían desaparecido del todo, pues testimonio de ellos nos da el Lazarillo:

\section{TRACTADO CUARTO}

Cómo Lázaro se asentó con un fraile de la Merced, y de lo que le acaesció con él

Hube de buscar el cuarto [amo], y este fue un fraile de la Merced, que las mujercillas [prostitutas] que digo me encaminaron, al cual ellas le llamaban pariente. Gran enemigo del coro y de comer en el convento, perdido por andar

importa qué sea la tierra, / sino que nos precipitamos al juego, / que es nuestro perpetuo desvelo. / Lo que se hace en la taberna, / donde el dinero es copero, / esto sí importa averiguarlo. / ¡Pero escuchad lo que os voy a decir!”. La cita y traducción de Cantos de Goliardo (Carmina Burana) (1981), pp. 290- 291.

${ }^{23}$ Una traducción correcta de estos versos es la siguiente: «Unos juegan, otros beben, / otros viven desenfrenadamente». La cita y la traducción se toman de por Cantos de Goliardo (Carmina Burana) (1981), p. 291.

${ }^{24}$ T. De Castro (2000), pp. 10-26. 
fuera, amicísimo de negocios seglares y visitar; tanto, que pienso que rompía él más zapatos que todo el convento. Este me dio los primeros zapatos que rompí en mi vida; mas no me duraron ocho días, ni yo pude con su trote durar más. Y por esto, y por otras cosillas que no digo, salí de él. ${ }^{25}$

\section{La evolución literaria del goliardo}

A partir de todo este compendio de textos áureos y de sus análisis puede observarse cómo las similitudes entre goliardos medievales y los del Siglo de Oro son suficientemente obvias, pues las actitudes hacia la vida y sus actividades (el vicio en diversos aspectos, la necesidad de supervivencia en muchos de los casos, el gusto por la vida despreocupada en otros) permiten advertir que, pese a que se haya perdido la etiqueta de goliardos, estos seguían existiendo. Lo que se deduce de los testimonios españoles no es en absoluto descabellado, y simplemente confirma lo que otros autores de algún modo ya detectaron para el resto de Europa. En su trabajo clásico, A. A. Parker indicaba que el Liber Vagatorum (c. 1520) nombra a «los mendigos cultos, jóvenes dedicados al estudio o estudiantes vagos» ${ }^{26} \mathrm{La}$ existencia de estos monjes y estudiantes mendigos, herederos por sus características de la ordo vagorum medieval, en el Siglo de Oro es, por tanto, una verdad histórica ineludible. Sin embargo, la gran diferencia entre unos y otros no radica en su existencia histórica, sino literaria. Es evidente que hubo diferencias históricas entre los goliardos de uno y otro período: los usos sociales, las costumbres, los ropajes, los hechos históricos y, con todo ello, las mentalidades, evolucionaban y los goliardos no podían verse libres de tal proceso. Y tampoco se libraron de una evolución literaria.

Aunque probablemente nunca sabremos si todos los carmina goliárdicos medievales son obra de verdaderos goliardos -siempre pudo haber algún que otro imitador-, los hallazgos en los monasterios de Benediktbeuern y Ripoll (Carmina Burana y Carmina Rivipullensia, respectivamente), así como en la Universidad de Cambridge (Carmina Cantabrigensia), focos todos ellos de culto y estudio, indica que los goliardos medievales se dedicaron no sólo a la vida de los vagos, sino que dejaron testimonio escrito de ello. Por contra, la diferencia con los goliardos del Siglo de Oro se fundamenta en el hecho de que, aparte de alguna que otra rara excepción, el goliardo ya no escribe. Su evolución le ha llevado a convertirse en personaje literario, no en autor. Ninguna de las obras arriba vistas son obra de goliardos, pero en dichos escritos sí aparecen estos clérigos -estudiantes o eclesiásticos- vagantes, personajes que tal vez no sean sino un homenaje a los viejos buenos tiempos, despreocupados y excitantes, que los autores de los textos citados vivieron cuando eran estudiantes, y quienes pudieron ser testigos -si no ser

\footnotetext{
${ }^{25}$ A. de Valdés (2003), p. 189.

${ }^{26}$ A. A. Parker (1971), p. 45.
} 
partícipes ellos mismos- de aventuras semejantes, vivencias que les habría provisto de buenos materiales en los que inspirarse para sus obras.

En todo caso, la evolución está ahí, con la aparición de un personaje literario a partir de otro real. La figura del estudiante cumple, pues, las mismas funciones que el pícaro: ${ }^{27}$ por un lado, el prodesse, un personaje truhanesco cuyas actividades daban pie a narrar sus artimañas, advirtiendo al lector acerca de estos personajes, así como la defensa de la honra, cosa que no tenían ni el pícaro ni el goliardo. Por otro lado, el delectare, puesto que el goliardo era un personaje que se prestaba a crear situaciones humorísticas, algo que no es extraño en los textos goliárdicos medievales.

\section{Conclusiones}

Parece claro que parte de los estudiantes del Siglo de Oro sólo tenían de estudiantes la etiqueta y poco más. Pero, obviamente, el ambiente en que se movían, así como sus actividades, coinciden con los de los goliardos medievales. Incluso sus grupos, tanto entre los que se veían abocados a la goliardía por necesidad o lo eran por vicio, como en cuanto a los tipos de trucos y vicios a que se dedicaban. No eran, como indicaba M. Chevalier, «tontos»; es posible que en los grupos de goliardos, algunos tuviesen menos luces que el resto, pero en una lucha por la supervivencia, uno tenía que ser muy listo -tanto respecto a su inteligencia como a su habilidad para aplicar sus engaños- o la sociedad misma se encargaría de eliminarlo al descubrir sus trampas, bien enviándolo a galeras -como leímos en el escrito cervantino-, bien escarmentados por sus víctimas. El buen estudiante pícaro, el buen goliardo, aprendía con la experiencia, y en su mundo sólo sobrevivían los mejores.

La figura del goliardo estudiantil estaba condenado a seguir existiendo, y daría igual que las universidades se hubiesen fundado en el siglo XII que en el XVI, pues en todas aparecían esos ingredientes de estudio e iglesia, a los que se añadía el nada despreciable factor de una juventud ávida de disfrutar la vida. La afirmación de Chevalier en cuanto que «la práctica de la burla que se enraiza en el escolar del folklore contagió al estudiante ${ }^{28}$ me parece absolutamente fuera de lugar teniendo en cuenta el análisis histórico-literario desarrollado en esta investigación: los goliardos del Siglo de Oro no se contagian de las burlas, ni eran los herederos de los medievales. No eran herederos de nada, porque ellos mismos eran tan goliardos como los anteriores. A cualquiera de ellos le podríamos oír, en un juego de palabras, jarra de cerveza en mano, algo así como Primum «bibere», deinde philosophare. No tratemos, eso sí, de preguntarnos si lo hubiese dicho alguien del siglo XII o del XVI. Cambiaban las épocas, los conocimientos, las modas... el

\footnotetext{
${ }^{27}$ J. M. Díez Borque (1976), p. 223, en el plano teatral, habla de «los caracteres arrufianados y picarescos con que los que le define [al estudiante] y utiliza la comedia».

${ }^{28}$ Conferencia de M. Chevalier (1999-2000).
} 
goliardo cambiaba de tiempo, de ropajes, mas no de personalidad. Las circunstancias históricas que permitieron también la aparición del pícaro en la sociedad y la literatura hicieron que el goliardo, quien apenas había gozado de presencia en la literatura española medieval, tuviese ahora un gran desarrollo y difusión.

En ese sentido, y considerando los puntos comunes entre goliardos estudiantes y pícaros -en ocasiones, un mismo personaje amalgama todo-, es necesario preguntarse si acaso el pícaro español no deberá también su existencia a los goliardos que, en el medievo, habrían sido el embrión que acabaría por desarrollarse siglos más tarde, alcanzando su punto álgido en Lázaro de Tormes. De ser así, podría trazarse todo un cuadro evolutivo del pícaro como personaje, lo cual permitiría comprender mejor tanto los rasgos que desarrolló y que perdió con respecto a sus antepasados medievales. Asimismo, podría observarse cómo influyeron las circunstancias históricas en su pervivencia, desarrollo y adecuación a cada momento, siempre como elemento subversivo, aparte de la sociedad y las normas establecidas, cuestiones todas ellas que exceden los propósitos de este trabajo que, si no ha cerrado muchas preguntas, si espera al menos haber abierto algunas nuevas.

\section{Obras citadas}

AJo GonZÁleZ De RAPANIEgos y SÁInZ DE ZÚÑIGA, C. Maria: Historia de las Universidades Hispánicas: Orígenes y desarrollo desde su aparición a nuestros dias, Madrid, Artes Gráficas Argés, 1959-1972.

Alemán, Mateo: Guzmán de Alfarache, edición de Benito Brancaforte, Madrid, Cátedra, 1984, tercera edición, vol. II.

ANÓNIMO: Segunda parte de Lazarillo de Tormes, en SEVILla ARROYO, Florencio (ed.): La Novela Picaresca Española, Madrid, Castalia, 2001, pp. 1-45.

BoIX JovANÍ, Alfonso: «La seducción femenina a través de la literatura medieval», Asparkia, 10 (1999), pp. 15-28.

Cantos de Goliardo (Carmina Burana), prólogo de Carlos Yarza, traducción de Lluís Moles, Barcelona-Caracas-México, Seix Barral, 1981.

CASTILlo SolóRZANo, Alonso de: Aventuras del Bachiller Trapaza [http://www.cervantesvirtual.com/servlet/SirveObras/0104895254425939 0200035/p0000001.htm\#I_4_ Página web visitada el 2 de febrero de 2004].

CASTRO, Teresa de: «Tabernas y taberneros en el Reino de Granada». En Historia 16, Madrid, Año XXIV, no 292, Agosto 2000, pp. 10-26.

Cervantes, Miguel de: Los trabajos de Persiles y Sigismunda. Edición, introducción y notas de Juan Bautista Avalle-Arce. Madrid, Castalia, 1985 . 
Covarrubias OROzCo, Sebastián de: Tesoro de la Lengua Castellana o Española, Madrid, Turner, 1979.

Chevalier, Maxime: «Un personaje folklórico de la literatura del siglo de oro: El estudiante», en PIÑERo Ramírez, Pedro M.- Rogelio ReYes CANO, Seis Lecciones sobre la España de los Siglos de Oro (Literatura e Historia), Sevilla-Bordeaux, Universidad de Sevilla-Université de Bordeaux III, 1981, pp. 39-58.

Diccionario de la Lengua Española, Madrid, Real Academia Española, 1992.

DíEZ BorQue, José Ma: Sociología de la Comedia Española del Siglo XVII, Madrid, Cátedra, 1976.

El Sacrosanto y Ecuménico Concilio de Trento, traducido al idioma castellano por D. Ignacio Lopez de Ayala. Agrégase el texto latino corregido segun la edicion auténtica de Roma, publicada en 1564. Nueva edición. París, Libreria de Rosa y Bouret, 1857.

EnCINA, Juan del: Auto del Repelón, en ENCINA, Juan del - Lucas FERNÁNDEZ:

Teatro, selección, edición y notas de Esteban Gutiérrez, Barcelona, Orbis-Fabbri, 1994, pp. 51-83.

GARCÍA MERCADAL, J.: Estudiantes, sopistas y pícaros, Madrid, Plutarco, 1934.

GonzÁleZ, Gregorio: Guitón Onofre, en SEVILla ARroyo, Florencio (ed.), La Novela Picaresca Española, Madrid, Castalia, 2001, pp. 341-392.

PARKER, Alexander A.: Los Pícaros en la Literatura. La novela picaresca en España y Europa (1599- 1753), versión española de Rodolfo Arévalo Mackry, Madrid, Gredos, 1971 (edición original: Literature and the Delinquent. The picaresque novel in Spain and Europe, 1599-1753, Edinburgh (Scotland), Edinburgh University Press, 1967).

PAUL, Jacques: Historia Intelectual del Occidente Medieval, traducción de Dolores Mascarell, Madrid, Cátedra, 2003 (título original: Histoire intellectuelle de l'Occident médiéval).

Poesía Goliárdica, traducción métrica de Miguel Requena, Barcelona, Acantilado Quaderns Crema, 2003.

QueVEDo, Francisco de: La Vida del Buscón, edición, prólogo y notas de Fernando

Cabo Aseguinolaza con un estudio preliminar de Fernando Lázaro Carreter, Barcelona, Crítica, 1993.

REQUenA, Miguel: «Introducción», en Poesía Goliárdica. Traducción métrica de Miguel Requena, Barcelona, Acantilado -Quaderns Crema, 2003, pp. 1318.

Simón-DíAZ, José: Los estudiantes de Madrid en el Siglo de Oro, Madrid, Ayuntamiento de Madrid Delegación de Educación - Instituto de Estudios Madrileños del CSIC (Aula de Cultura. Curso sobre Historia de Madrid), 1966. 
TORRemochA, Margarita: La Vida Estudiantil en el Antiguo Régimen, Madrid, Alianza, 1998.

VALDÉS, Alfonso de: La Vida del Lazarillo de Tormes, y de sus fortunas y adversidades. Introducción de Rosa Navarro Durán. Edición y notas de Milagros Rodríguez Cáceres. Barcelona, Octaedro, 2003. [Lazarillo 2003]

YARZA, Carlos: «Prólogo», en Cantos de Goliardo (Carmina Burana), prólogo de Carlos Yarza, traducción de Lluís Moles Barcelona-Caracas-México, Seix Barral, 1981, pp. 9-42. 